\title{
Analysis of distribution system in beef marketing
}

G Asgari Jaffarabadi, A Vahabi

Islamic Azad University of Varamin, Varamin, Tehran, Islamic Republic of Iran

Email:ghobad@gmail.com

Introduction Nowadays the marketing of both livestock and meat is a complex process. The reflection of consumer preference for meat back through the marketing system to the original producer is highly dependent upon a national marketing strategy. The marketing concept holds that the key to achieving organizational goals consists in determining the needs and wants of target markets and delivering the desired satisfactions (Cross and Savell, 1994). In this study we tried to investigate the possible distribution paths of beef marketing, also comparing consumer preferences with producers and distributors. The possible correlations among various variables were also tested.

Materials and methods In order to have an adequate sample size, the region of capital of Iran, Tehran was selected as target population in the year 2008. Random sampling was applied for field study and information was collected using designed questionnaires. Of five statistical populations, 60 producers, 17 industrial slaughterhouses, 104 wholesalers, 700 retailers and finally 100 consumers, were sampled. The samples were finally divided into two study groups where consumers in one group were separated from producers, processors and sellers as another group and these two groups were compared and evaluated for 21 different variables such as effect of processing units, management of official distribution, refrigerating system, sanitation, slaughter quality, local sale centres, chain stores, governmental support, proper packing, delivery costs, imported frozen beef, content of fat, etc. Two statistical methods, Chi-Square test for testing the significance of differences between two groups and T-test for testing the magnitude of correlation coefficients among different outputs were applied. The four known distribution paths are shown in Figure 1.

\begin{tabular}{|c|l|c|}
\hline path & \multicolumn{1}{|c|}{ description } & percent \\
\hline 1 & producer $\rightarrow$ slaughterhouse $\rightarrow$ wholesaler (associations) $\rightarrow$ retailer $\rightarrow$ consumer & $7 / 35$ \\
\hline 2 & producer $\rightarrow$ slaughterhouse $\rightarrow$ wholesaler (processing units) $\rightarrow$ retailer $\rightarrow$ consumer & 7.14 \\
\hline 3 & producer $\rightarrow$ dealer $\rightarrow$ slaughterhouse $\rightarrow$ retailer $\rightarrow$ consumer & 7.15 \\
\hline 4 & producer $\rightarrow$ dealer $\rightarrow$ slaughterhouse $\rightarrow$ wholesaler $\rightarrow$ retailer $\rightarrow$ consumer & $7 / 36$ \\
\hline
\end{tabular}

Figure 1 Four distribution paths in beef marketing

Results In 51\% of known distribution paths, dealers played the main role while processing units had 14\% participation in distribution. The remaining 35\% was under control of beef associations. Price difference of beef between two paths, one including dealers and another without dealers is $7.6 \%$ of final sale price for producer and $53.33 \%$ of total marketing costs. In paths 3 and 4, the difference in final price is imposed to consumer while in paths 1 and 2, this difference shows the changes of price among final distributors in four possible paths. Statistical analysis showed significant differences between two groups for some variables like governmental support, management of official distribution, refrigerating system, sanitation, content of fat, proper packing and imported frozen beef. Also $29 \%$ of consumers and $34 \%$ of producers agreed with local sale centers while $71 \%$ of consumers and $66 \%$ of producers agreed with distribution via processing units. In general $68.5 \%$ of samples agreed with distribution via processing units and it was believed to be the appropriate system of beef distribution.

Conclusions According to final results, some solutions may correct the current systems and increase the efficiency of marketing. Some local sale centers can be established which have sale representatives in local small marketplaces. Distribution must be exclusive to these centers. In the lack of processing units these local centers may improve the distribution. In the presence of processing units, some points like packing the beef in proper packages or producing low fat beef must be concerned. Also it is recommended to have diversity in packing and sizes according to consumers demand. The small local markets must be exclusive representatives of processing units, The quality of livestock production and slaughter must be under intensive supervision.

\section{References}

Cross, H.R., and J.W. Savell. 1994. What do we need for a value-based beef marketing system?. Meat Science 36, $19-27$. Dewettinck, K., F. Van Bockstaele, B. Kühne, D. Van de Walle, T.M. Courtens and X. Gellynck. 2008. Nutritional value of bread: Influence of processing, food interaction and consumer perception. Journal of Cereal Science 48, 243-257. 